\title{
Intertemporal Asset Pricing: Preliminary Evidence from an Emerging Economy
}

\author{
Amna Rehman ${ }^{*}$ and Nawazish Mirza**
}

\begin{abstract}
In this paper, we test a simple Merton-style (1973) intertemporal capital asset pricing model (ICAPM) by allowing for time variations in certain key state variables for a sample of firms listed on the Karachi Stock Exchange. We evaluate the model's ability to account for returns on portfolios sorted by size, book-tomarket ratio, and momentum. Our findings provide evidence of an intertemporal asset pricing setting with significant coefficients for innovations in state variables. Innovations in dividend yield, term, and risk-free rates are systematically priced in time series of returns and should be considered when evaluating the risk premium for investments. We do not find the market premium to be a significant variable, which suggests that a traditional capital asset pricing model is unable to capture variations in stock returns for our sample period. These results favor the use of an ICAPM framework for optimal decision-making.
\end{abstract}

Keywords: ICAPM, business risk, financial risk, Karachi Stock Exchange.

JEL classification: G10, G11, G12.

\section{Introduction}

The asset pricing literature originates from Markowitz's (1952) proposition of mean variance efficiency, based on which, Treynor (1961/1999), Treynor and Black (1973), Sharpe (1964), Lintner (1965), and Mossin (1966), proposed initial versions of asset pricing models. These models are based on stock's sensitivity to the market, resulting in a market premium for the investor. One of the key assumptions underlying these asset-pricing propositions was the discrete investment period. However, the assumption seemed too stringent because investors are likely to rebalance their portfolios from one period to another. This limitation was addressed by introducing an intertemporal choice by Samuelson (1969),

\footnotetext{
* The author is assistant professor of business administration at the Lahore School of Economics, and can be contacted at amna_rehman555@yahoo.com.

** The author is associate professor of finance at the Center for Research in Economics and Business at the Lahore School of Economics, and can be contacted at nawazishmirza@gmail.com.
} 
Hakansson (1970), and Fama (1970), who argued that investors make portfolio and consumption decisions in various time periods.

Merton (1973) proposed an intertemporal capital asset pricing model (ICAPM), which assumes a continuous investment setting. This facilitated the construction of a framework that was more realistic and, at same time, more tractable than the discrete time model. Merton suggested that when there is stochastic variation in investment opportunities, there is likely to be a risk premium associated with innovations (time variations) in the state variables that describe the investment opportunities. The innovations in the selected state variables are able to identify shocks in the investment opportunity set.

In this paper, we estimate a simple ICAPM by allowing for time variations in certain key state variables and evaluate the model's ability to account for the returns on portfolios sorted by size, book-to-market ratio, and momentum. Since asset pricing models are an important input in estimating investment appraisals, project feasibility, and the cost of equity capital, this study aims to facilitate corporate decision makers and stock market investors in making the appropriate estimates for their investment strategies. Pakistan has three stock exchanges, ${ }^{1}$ of which the Karachi Stock Exchange (KSE) features the largest market capitalization, trading volume, and liquidity (Table 1).

The paper is organized as follows. Section 2 outlines the research methodology used, Section 3 presents our empirical findings, and Section 4 concludes the study.

\footnotetext{
${ }^{1}$ These include the Karachi Stock exchange (KSE), Lahore Stock Exchange, and Islamabad Stock Exchange.
} 
Table 1: Salient features of KSE

\begin{tabular}{|c|c|c|c|c|c|}
\hline Feature & 2006 & 2007 & 2008 & 2009 & 2010 \\
\hline Total number of listed companies & 652 & 654 & 653 & 651 & 651 \\
\hline Total listed capital (PKR) & $519,270.17$ & $671,255.82$ & $750,477.55$ & $814,478.74$ & $909,968.03$ \\
\hline Total market capitalization (PKR) & $2,771,113.94$ & $4,329,909.79$ & $1,858,698.90$ & $2,705,879.83$ & $2,721,604.94$ \\
\hline KSE-100 ${ }^{\mathrm{TM}}$ index & $10,040.50$ & $14,075.83$ & $5,865.01$ & $9,386.92$ & 9,705 \\
\hline KSE-30 ${ }^{\mathrm{TM}}$ index & $12,521.54$ & $16,717.10$ & $5,485.33$ & $9,849.92$ & $9,641.55$ \\
\hline KSE all share index & $6,770.06$ & $9,956.76$ & $4,400.76$ & $6,665.55$ & $6,783.70$ \\
\hline New companies listed during the year & 9 & 14 & 10 & 4 & 6 \\
\hline Listed capital of new companies (PKR) & $14,789.76$ & $57,239.92$ & $15,312.12$ & $8,755.73$ & $32,538.44$ \\
\hline New debt instruments listed during the year & 3 & 3 & 7 & 1 & 4 \\
\hline Listed capital of new debt instruments (PKR) & $3,400.00$ & $6,500.00$ & $26,500.00$ & $3,000.00$ & $5,650.18$ \\
\hline Average daily turnover (shares in millions) & 260.69 & 268.23 & 146.55 & 179.88 & 144.16 \\
\hline Average value of daily turnover (PKR) & $31,610.71$ & $25,262.97$ & $14,228.35$ & $7,450.75$ & $4,778.90$ \\
\hline Average daily turnover (Future ${ }^{\mathrm{TM}}$ ) (YTD) & 82.68 & 61.69 & 30.76 & 1.03 & 5.17 \\
\hline Average value of daily turnover (YTD) & $13,587.63$ & $9,077.61$ & $5,229.97$ & 89.66 & 416.1 \\
\hline
\end{tabular}

Note: All monetary data in millions. PKR $1 \sim$ USD 95. Source: KSE website. 


\section{Research Methodology}

\subsection{Sample Selection}

We consider a sample period from 1 July 1997 to 30 June 2007. The reason for choosing this sample period is to be able to estimate the model over a relatively smooth period of investment activity. In August 2008, the KSE index started to follow an extreme downward trend and the stock market was not able to normalize for about eight months. During this time, there was low trading. Therefore, in order to avoid extreme results due to market conditions, the period post-June 2007 was not included in the sample period. The following criteria were employed to select stocks from individual sectors.

1. All selected stocks were listed on the KSE.

2. In order to avoid thinly traded stocks, only those stocks with non-zero returns for at least 90 percent of the trading days were included in the sample. The selected stocks comprised stocks from all sectors.

3. Data on daily price, book value, market value of equity, and market capitalization should be available for the stocks in the sample.

The secondary data was collected from the KSE's website, and comprised daily stock prices and the KSE-100 index value. The overnight repo rate was used as a proxy for the risk-free rate, data on which was collected from the JS Group's treasury. Data on book value and market capitalization was collected from the annual reports of the companies in the sample. Table 2 presents our sample's composition. 
Table 2: Year-wise sample composition

\begin{tabular}{|c|c|c|}
\hline Year & No. of firms in the sample & Thinly traded stocks \\
\hline 1998 & 120 & 70 \\
\hline 1999 & 131 & 73 \\
\hline 2000 & 131 & 84 \\
\hline 2001 & 135 & 86 \\
\hline 2002 & 138 & 95 \\
\hline 2003 & 140 & 110 \\
\hline 2004 & 140 & 135 \\
\hline 2005 & 145 & 140 \\
\hline 2006 & 150 & 153 \\
\hline 2007 & 150 & 160 \\
\hline
\end{tabular}

Note: We classify thinly traded stocks as those that yield zero returns for more than 10 percent of the observations during the sample period.

Source: Authors' calculations.

\subsection{Portfolio Formation}

Fama and French (1992) suggest that stock returns are also influenced by firm characteristics such as firm size in terms of market capitalization and firm value in terms of its book-to-market ratio. They observe that glamour/growth and value stocks perform better than the market, and that firms with a high book-to-market value tend to be in constant financial distress while those with a low book-to-market value are associated with sustained profitability and future growth. Moreover, stocks with small market capitalization (small firms) tend to be more profitable than large stocks.

Carhart (1997) and Liew and Vassalou (2000) have augmented the Fama and French size-and-value model with a momentum factor. Liew and Vassalou form portfolios based on a high book-to-market value minus low book-to-market value (HML), small market capitalization to big market capitalization (SML), and momentum up minus down (UMD) in an attempt to capture all three risk factors, namely, size, book-to-market value, and momentum. We adopt Liew and Vassalou's portfolio formation methodology in order to capture the risk associated with firm characteristics-i.e., size, book-to-market value, and momentum-in order to test the relevance of the size, value, and momentum risk factors in an emerging stock exchange such as the KSE. 
We construct 12 equally weighted portfolios sorted by size, bookto-market, and momentum: HBU, HBD, HSU, HSD, MBU, MBD, MSU, MSD, LBU, LBD, LSU, and LSD. For each year from 1 July 1997 to 30 June 2007, we take 30 June as the date on which to rebalance the portfolios according to book-to-market, size, and momentum. Accordingly, the 12 portfolios are rebalanced for each year.

\subsection{Model Specification}

The ICAPM is an augmented capital asset pricing model (CAPM) incorporating innovation factors. The model is expressed as follows:

$$
R_{i t}=R_{f}+\left(R_{m t}-R_{f}\right) \beta_{1 t}+\left(\widehat{u}_{\text {divYld }}\right) \beta_{2 t}+\left(\widehat{u}_{t e r m}\right) \beta_{3 t}+\left(\widehat{u}_{r f}\right) \beta_{4 t}
$$

$t=1,2,3, \ldots, 2,600$, with $t$ daily observations. $R_{i t}$ is the expected return on stock $i, R_{m t}-R_{f}$ represents the market risk premium, $\hat{u}_{d i v Y l d}$ is the innovation in the dividend yield of the index (KSE-100), $\hat{u}_{\text {term }}$ is the innovation in the term factor of the yield curve, and $\hat{u}_{R_{f}}$ is the innovation in the risk-free rate, i.e., the daily repo rate. The coefficients $\beta_{1 t}, \beta_{2 t}, \beta_{3 t}$, and $\beta_{4 t}$ represent the risk sensitivities of the independent variables.

We use the following time series framework to test the ICAPM:

$$
R_{i t}-R_{f}=\alpha_{i}+\left(R_{m t}-R_{f}\right) \beta_{1 t}+\left(\hat{u}_{d i v Y l d}\right) \beta_{2 t}+\left(\hat{u}_{t e r m}\right) \beta_{3 t}+\left(\hat{u}_{r f}\right) \beta_{4 t}+\epsilon_{t}
$$

where $E R_{i t}=R_{i t}-R_{f}$ represents the excess return on stock $i$ in time $t, \alpha_{i}$ is the intercept of the regression equation representing the nonmarket return component, and $\epsilon_{t}$ represents the error term, which is the random return component due to unexpected events related to a particular stock, $i$. The coefficients $\beta_{1 t}, \beta_{2 t}, \beta_{3 t}$, and $\beta_{4 t}$ are the risk sensitivities of returns for market risk, innovation in the dividend yield of the index (KSE-100), innovation in the term factor, and innovation in the risk-free rate. The ICAPM for an individual stock can also be expressed for a portfolio by replacing $i$ with $p$ :

$$
E R_{p t}=\alpha_{p}+\left(R_{m t}-R_{f}\right) \beta_{1 t}+\left(\widehat{u}_{d i v Y l d}\right) \beta_{2 t}+\left(\widehat{u}_{t e r m}\right) \beta_{3 t}+\left(\widehat{u}_{r f}\right) \beta_{4 t}+\epsilon_{t}
$$

where $E R_{p t}$ is the excess return of the portfolio in time $t$, and $\alpha_{p}$ is the average of all individual alphas of the stocks included in the equally weighted portfolio. 


\subsection{Estimation of Variables}

The dependent variable in the ICAPM is the excess portfolio return-the return over and above the risk-free return, represented by $E R_{p t}$. The independent variables are excess market return and a set of state variables that include innovations in DIV, TERM, and $R_{f}$, which help to forecast future market portfolio returns. The innovations in these variables are expected to account for common time varying patterns in portfolio returns portfolios and capture uncertainty about future investment opportunities. These variables are chosen to model two aspects of the investment opportunity set: the yield curve and the conditional distribution of asset returns. The yield curve is an important part of the investment opportunity set; the daily repo rate $(R F)$ and term spread (TERM) are, therefore, used to capture variations in the level and slope of the yield curve.

The conditional distribution of asset returns is also an integral part of the investment opportunity set. Petkova (2006) suggests that the conditional distribution of asset returns, as characterized by its mean and variance, changes over time. The time-series literature highlights a set of variables that proxy for variation in the mean and variance of returns. The aggregate dividend yield $(D I V)$ and interest rates are among the most common variables used to proxy variation in the mean and variance of returns. Subsequently, these state variables are most likely to capture investors' hedging concerns related to changes in the interest rate and variations in risk premiums.

Viale, Kolari, and Fraser (2009) suggest that the innovations in the slope of the yield curve are closely related to the real business cycle. The yield curve is steeper near the trough of the real business cycle (with negative shocks signaling a possible shift toward good times) and relatively flat near the peak (with positive shocks signaling a possible shift toward bad times). From an ICAPM perspective, the negative sign of the TERM premium implies that stocks constitute a hedge against future negative shocks to consumption growth. Fama and French (1989) argue that the values of the term spread indicate that expected market returns are high during recessions and low during expansions. Their study shows that the term spread tracks short-term shocks and fluctuations in the business cycle. Positive shocks to the term premium are associated with bad times with respect to business conditions, while negative shocks are associated with good times. 
According to Petkova and Zhang (2004), value stocks are riskier than growth stocks in bearish markets, but less risky during good times. Cornell (1999) and Campbell and Vuolteenaho (2004) highlight another aspect of shocks to the term spread and HML portfolio- the context of the cash flow maturities of assets. They propose that value stocks are lowduration assets compared to growth stocks, which makes them similar to short-term bonds and, therefore, more sensitive to shocks in the short term, i.e., the short end of the yield curve. Similarly, growth stocks are highduration assets, which makes them similar to long-term bonds, and are more sensitive to shocks in the long run, i.e., the long end of the yield curve or term structure.

Chan and Chen (1991) argue that small firms tend to lose their market value due to poor performance; they are likely to face cash flow constraints and have high financial leverage, and are less likely to survive during poor economic conditions. Consequently, small firms are more sensitive to news about the state of the business cycle. We test the ICAPM to determine whether unexpected changes in the state variables explained above improve the explanatory power of the standard CAPM.

The returns on an individual stock $i$ are estimated as follows:

$$
R_{i t}=\ln \left[\frac{P_{t}}{P_{t-1}}\right]
$$

where $P_{t}$ and $P_{t-1}$ are the closing prices on day $t$ and $t-1$, respectively. $R_{p t}$, which represents portfolio returns, is the weighted average return on individual stocks:

$$
R_{p t}=\sum_{i=1}^{N} W_{i} R_{i t}
$$

Similarly, market portfolio returns can be estimated as follows:

$$
R_{m t}=L N\left[\frac{K S E(100)_{t}}{K S E(100)_{t-1}}\right]
$$

where $K S E(100)_{t}$ and $K S E(100)_{t-1}$ are the closing index values on day $t$ and $t-1$, respectively. The portfolio and market returns are used to estimate the excess portfolio returns $\left(R_{p t}-R_{f}\right)$ and market risk premium $\left(R_{m t}-R_{f}\right)$. 
The innovation factors are taken as the difference between the actual (daily value) and expected (monthly average) of a variable. The innovation in the dividend yield of the KSE-100 index $\hat{u}_{\text {divYld }}$ is estimated as the difference between the daily dividend yield and monthly average of the dividend yield of the index (KSE-100). The daily dividend yield of the index (KSE$100)$ is based on its dividends and daily index (KSE-100) values. The dividend of the index is the weighted average of the dividends of all the stocks in the index (KSE-100); the daily dividend of the index is, therefore, tabulated on a daily basis because the companies listed on the KSE give dividends on different dates. The dividend yield of the KSE-100 index is tabulated as its daily dividend yield divided by the daily KSE-100 index values. The term value is tabulated as the difference between the long-term (six-month) repo rate and the short-term (overnight) repo rate. The innovation in the term variable $\left(\hat{u}_{\text {term }}\right)$ is estimated as the difference between the daily term value and its monthly average. The innovation in the risk-free rate $\left(\hat{u}_{R_{f}}\right)$ is estimated as the difference between the daily repo rate and its monthly average.

\section{Empirical Results}

Table 3 presents the empirical results of the 12 individual ICAPM regressions on 12 size, book-to-market, and momentum portfolios. The coefficient of the market risk premium is insignificant for all 12 portfolios. Since the intercept $\left(\alpha_{p}\right)$ is found to be significant for five out of the 12 portfolios, i.e., BHU, BLU, BMU, SHU, and SMU, the beta coefficients of the independent variables for these portfolios are deemed irrelevant.

The coefficients of the innovation in the dividend yield of the index $\left(\beta_{2}\right)$ are found to be significant at 99 percent for five portfolios, i.e., BHD, SHD, SLD, SLU, and SMD. The innovation in the dividend yield of the index reflects the business risk associated with the overall market. Even if the index is dominated by the leading stocks, the innovation in the dividend yields of these stocks would lead to a similar trend in the innovation in the dividend yield in the overall market. Small firms tend to be more sensitive to such business risk due to their lack of financial flexibility and narrow scope of business. An innovation in the dividend yield of the index is, therefore, found to be significant in all portfolios with small companies' stocks. Investors in KSE-traded stocks thus require a premium when investing in small stocks. 
The daily repo rate $(R F)$ and term spread (TERM) capture the variations in the level and slope of the yield curve. The coefficients of innovation in term $\left(\beta_{3}\right)$ are found to be significant at 99 percent for six portfolios, i.e., BHD, BMD, SHD, SLD, SLU, and SMD. The coefficients of innovation in the risk-free rate $\left(\beta_{4}\right)$ are found to be significant at 99 percent for five portfolios, i.e. BHD, BLD, BMD, SLD, and SLU; SMD is significant, however, at 95 percent. Our evidence demonstrates that innovations in term and the risk-free rate are significant in the majority of the portfolios that included small firms. Changes in financing cost arise either because of a change in the firm's capital structure or due to a change in the yield curve- this reflects the financial risks.

As mentioned earlier, the yield curve is an important part of the investment opportunity set because the innovation in the slope of the yield curve is closely related to the business cycle. Since small firms are likely to face cash flow constraints and have high financial leverage, they are less likely to survive during poor economic conditions (Viale et al., 2009), and are, therefore, more sensitive to news about the state of the business cycle and have a high financial risk. Small firms also have a low capacity to absorb additional risk, be it financial or business. Therefore, investors require a premium when investing in small firms. During the sample period (1 July 1997 to 30 June 2007), firms were exposed to high business risk due to the increase in competition that arose during the government's deregulation and privatization efforts. Moreover, since 2003, interest rates in Pakistan have risen, which has increased the financial risk for small firms listed on the KSE.

Large firms have a higher capacity to absorb business and financial risk. Therefore, if we consider only the size factor, large firms are relatively less affected by innovations in term value and the risk-free rate. However, value stocks are short-duration assets compared to growth stocks, which makes them similar to short-term bonds and, therefore, more sensitive to shocks in the short term, i.e., the short end of the yield curve. In bad times value stocks are riskier than growth stocks, whereas they are less risky during good times (Petkova, 2006). Consequently, large firms with a high or medium book-to-market ratio tend to be sensitive to the innovation in term. Overall, our findings suggest that the ICAPM largely explains the time series of returns for portfolios that are controlled for size, value, and momentum effects. 
Table 3 reports the results of individual ICAPM regressions on 12 portfolios sorted by size, book-to-market, and momentum for the period 1 July 1997 to 30 June 2007 according to:

$$
E R_{p t}=\alpha_{p}+\left(R_{m t}-R_{f}\right) \beta_{1 t}+\left(\hat{u}_{d i v Y l d}\right) \beta_{2 t}+\left(\hat{u}_{t e r m}\right) \beta_{3 t}+\left(\hat{u}_{R f}\right) \beta_{4 t}+\epsilon_{t}
$$

where $E R_{p t}$ is the excess return on the portfolio in time $t$ and $\alpha_{p}$ is the average of all individual alphas of the stocks included in the portfolio. $\alpha_{p}$ is the intercept of the regression equation representing the nonmarket return component, while $\left(R_{m t}-R_{f}\right)$ represents the market risk premium. The coefficients $\beta_{1 t}, \beta_{2 t}, \beta_{3 t}$, and $\beta_{4 t}$ are, respectively, the risk sensitivities of returns for market risk, the innovation in dividend yield of the index (KSE-100), the innovation in the term factor, and the innovation in the risk free rate. $\epsilon_{t}$ is an error term that represents the random return component due to unexpected events related to a particular stock $i$. For the purpose of simplification, we assume that $\epsilon_{t}$ has a multivariate normal distribution and is independently and identically distributed over time. Columns $1,2,3$, 4 , and 5 report the estimates of $\alpha_{p}, \beta_{1 t}, \beta_{2 t}, \beta_{3 t}$, and $\beta_{4 t}$. Columns 6,7 , and 8 report the t-statistics for the estimates of $\alpha_{p}$ and $\beta_{t}, \beta_{2 t}, \beta_{3 t}$, and $\beta_{4 t}$. 
Table 3: ICAPM: Four-factor regressions on 12 portfolios sorted by size, book-to-market ratio, and momentum

\begin{tabular}{|c|c|c|c|c|c|c|c|c|c|c|}
\hline & $\alpha$ & $\beta_{1}$ & $\beta_{2}$ & $\beta_{3}$ & $\beta_{4}$ & $t(\alpha)$ & $t\left(\beta_{1}\right)$ & $t\left(\beta_{2}\right)$ & $t\left(\beta_{3}\right)$ & $t\left(\beta_{4}\right)$ \\
\hline $\mathrm{BHD}$ & 0.000448 & -0.027089 & -0.111428 & 0.352939 & -0.363339 & 1.226919 & -1.281405 & $-4.555941^{* * *}$ & $16.06064^{* * *}$ & $-15.54302^{* * *}$ \\
\hline $\mathrm{BHU}$ & 0.004665 & 0.001962 & 0.301166 & 0.295827 & -0.53496 & $13.76362^{* * * *}$ & 0.099987 & $13.26758^{* * *}$ & $14.50455^{* * *}$ & $-24.65744^{* * *}$ \\
\hline BLD & -0.000469 & -0.008034 & 0.0269 & 0.02752 & -0.247933 & -1.527326 & -0.451641 & 1.307114 & 1.488289 & $-12.60462^{* * *}$ \\
\hline BLU & 0.000963 & 0.006246 & 0.205916 & -0.023659 & -0.301867 & $3.237845^{* * *}$ & 0.362803 & $10.3378^{* * *}$ & -1.321924 & $-15.85604^{* * *}$ \\
\hline BMD & -0.000395 & 0.013302 & 0.023861 & 0.12061 & -0.320903 & -1.298105 & 0.755365 & 1.171167 & $6.58857^{* * *}$ & $-16.47938^{* * *}$ \\
\hline BMU & 0.00121 & 0.024333 & 0.189426 & 0.052285 & -0.317455 & $3.948205^{* * *}$ & 1.372035 & $9.23206^{* * *}$ & $2.836081^{* * *}$ & $-16.18756^{* * *}$ \\
\hline SHD & -0.000367 & 0.022624 & 0.107566 & 0.122653 & -0.021064 & -1.324707 & 1.411644 & $5.801088^{* * *}$ & $7.361967^{* * *}$ & -1.188553 \\
\hline SHU & 0.001762 & -0.004334 & 0.147087 & 0.210972 & -0.131708 & $4.637801^{* * *}$ & -0.19711 & $5.781973^{* * *}$ & $9.230102^{* * *}$ & $-5.41696^{* * *}$ \\
\hline SLD & -0.000527 & -0.033352 & 0.22429 & 0.289673 & 0.308581 & -1.31798 & -1.440598 & $8.373541^{* * *}$ & $12.03616^{* * *}$ & $12.05338^{* * *}$ \\
\hline SLU & 0.00029 & 0.013195 & 0.306259 & 0.34087 & 0.064533 & 0.770398 & 0.605121 & $12.13991^{* * *}$ & $15.03821^{* * *}$ & $2.67638^{* * *}$ \\
\hline SMD & $-6.70 \mathrm{E}-05$ & 0.007054 & 0.162021 & 0.070702 & 0.041539 & -0.230408 & 0.418837 & $8.314443^{* * *}$ & $4.038094^{* * *}$ & $2.230248^{* *}$ \\
\hline SMU & 0.001272 & -0.006873 & 0.102212 & 0.029978 & -0.036825 & $4.077093^{* * *}$ & -0.380646 & $4.892711^{* * *}$ & 1.597076 & $-1.844271^{*}$ \\
\hline
\end{tabular}

Note: ${ }^{*}=$ significant at 90 percent, ${ }^{* *}=$ significant at 95 percent,${ }^{* * *}=$ significant at 99 percent.

Source: Authors' calculations. 


\section{Conclusion}

Merton's (1973) ICAPM suggests that asset pricing should be dealt with using continuous time settings and innovations in state variables are systematically priced in stock returns. In this paper, we have tested a standard ICAPM for stocks listed on the KSE using innovations in dividend yield, term structure, and the risk-free rate to account for business and financial risk. The portfolios were constructed by size, value, and momentum to control for these premiums.

Our results reveal an insignificant market risk premium for all 12 portfolios. Small firms demonstrate greater sensitivity to business risk while the innovation in the dividend yield of the index was found to be significant for all the portfolios. The innovations in term and risk-free rate were significant in the majority of the portfolios that included small firms, implying that firms constrained by size are more sensitive to the state of the business cycle and face high financial risk. Small firms also have low capacity to absorb additional risk, warranting a higher risk premium.

Larger firms have a high risk-absorption capacity and are, therefore, less sensitive to innovations in term structure and risk-free rate. Value stocks demonstrate greater sensitivity to shocks in the short term, i.e., the short end of the yield curve. Larger firms with a high or medium book-to-market ratio tend to be sensitive to innovations in term. These findings point to a new dimension of premiums that are priced in stock returns, which should be considered when making investment decisions. 


\section{References}

Campbell, J., \& Vuolteenaho, T. (2004). Bad beta, good beta. American Economic Review, 94(5), 1249-1275.

Carhart, M. M. (1997). On persistence in mutual fund performance. Journal of Finance, 52(1), 57-82.

Chan, K. C., \& Chen, N.-F. (1991). Structural and return characteristics of small and large firms. Journal of Finance, 46, 1467-1484.

Cornell, B. (1999). Risk, duration, and capital budgeting: New evidence on some old questions. Journal of Business, 72(2), 183-200.

Fama, E. F. (1970). Multiperiod consumption-investment decisions. American Economic Review, 60(1), 163-174.

Fama, E. F., \& French, K. R. (1989). Business conditions and expected returns on stocks and bonds. Journal of Financial Economics, 25(1), 23-49.

Fama, E. F., \& French, K. R. (1992). The cross-section of expected returns. Journal of Finance, 47(2), 427-465.

Hakansson, N. (1970). Optimal investment and consumption strategies under risk for a class of utility functions. Econometrica, 38, 587-607.

Liew, J., \& Vassalou, M. (2000). Can book-to-market, size and momentum be risk factors that predict economic growth? Journal of Financial Economics, 57, 221-245.

Lintner, J. (1965). The valuation of risk assets and the selection of risk investments in stock portfolios and capital budgets. Review of Economics and Statistics, 47, 13-37.

Markowitz, H. (1952). Portfolio selection. Journal of Finance, 7(1), 77-91.

Merton, R. C. (1973). An intertemporal capital asset pricing model. Econometrica, 41, 867-887.

Mossin, J. (1966). Equilibrium in a capital asset market. Econometrica, 34, 768-783. 
Petkova, R. (2006). Do the Fama-French factors proxy for innovations in predictive variables? Journal of Finance, 61(2), 581-612.

Petkova, R., \& Zhang, L. (2004). Is value riskier than growth? Journal of Financial Economics, 78, 187-202.

Samuelson, P. A. (1969). Lifetime portfolio selection by dynamic stochastic programming. Review of Economics and Statistics, 51(3), 239-246.

Sharpe, W. (1964). Capital asset prices: A theory of market equilibrium under conditions of risk. Journal of Finance, 19(3), 425-442.

Treynor, J. L. (1999). Toward a theory of market value of risky assets. In R. A. Korajczyk (Ed.), Asset pricing and portfolio performance: Models, strategy, and performance metrics. London, UK: Risk Books. (Original work published 1961)

Treynor, J. L., \& Black, F. (1973). How to use security analysis to improve portfolio selection. Journal of Business, 46(1), 66-86.

Viale, A., Kolari, J., \& Fraser, D. (2009). Common risk factors in bank stocks. Journal of Banking and Finance, 33(3), 464-472. 
